\title{
Reinas venezolanas del siglo XX. Populismo, abstracción y Estado
}

\author{
Twentieth-century Venezuelan beauty pageant \\ queens. Populism, abstraction and State \\ Rainhas venezuelanas do século $\mathrm{XX}$. \\ Populismo, abstração e Estado
}

\section{Vicente Lecuna}

UNIVERSIDAD CENTRAL DE VENEZUELA， VENEZUELA

PhD, University of Pittsburgh. Profesor Asociado en la Universidad

Central de Venezuela. Entre sus publicaciones más importantes, se cuentan: La ciudad letrada en el planeta electrónico: La situación actual del intelectual latinoamericano (Folios,1999). "El Nuevo modo de vivir. 'Nocturno' de Lucas García y la violencia informal”' (en Voz y escritura. Revista de Estudios Literarios, 2016) y "Modern Dreams, Sinister Spaces" (en From Mall to Prison. El Helicoide's Downward Spiral. Terreform, 2017). Así mismo, se destaca su trabajo como editor en "La Venezuela de la escritura" (Revista Conciencia Activa, 2010) y en "Meneses en nuestros caminos" (Revista Conciencia Activa, 2013). Correo electrónico: vicentelecuna66@gmail.com

Artículo de investigación

Este trabajo forma parte de un libro que está escribiendo el autor sobre Parque Central.

Documento accesible en línea desde la siguiente dirección: http://revistas.javeriana.edu.co 


\section{Resumen}

Desde la mitad del siglo XX hasta finales de los años noventa la vanguardia cohabitó con el Estado venezolano en una relación compleja que fundó el sistema político nacional sobre la base de la literatura populista y el arte abstracto. En este artículo reviso algunas de la políticas verbales y visuales que acompañaron el tránsito de las dictaduras a la democracia en Venezuela. Para ello discuto algunos hitos de la vanguardia literaria, artística y política, así como dos "elecciones de reinas" que funcionaron como pivotes de la lucha democrática.

Palabras clave: vanguardia; Venezuela; reinas de belleza; artes plásticas; abstracción; elecciones

\section{Abstract}

From the middle of the 20th century to the end of the $1990 \mathrm{~s}$, avant-garde cohabited with the Venezuelan State in a complex relationship that founded the national political system on the basis of populist literature and abstract art. In this article, I review some of the verbal and visual policies that accompanied the transition from dictatorships to democracy in Venezuela. For this, I discuss some of the literary, artistic and political avant-garde milestones, as well as two "beauty pageant elections" that functioned as a driving force for the fight for democracy in this country.

Keywords: avant-garde; Venezuela; beauty queens; plastic arts; abstraction; elections

\section{Resumo}

Desde meados do século XX até finais dos anos noventa a vanguarda coabitava com o Estado venezuelano em um relacionamento complexo que fundou o sistema político nacional sobre a base da literatura populista e a arte abstrata. Neste artigo reviso algumas políticas verbais e visuais que acompanharam a transição das ditaduras para a democracia em Venezuela. Para isso, discuto alguns marcos da vanguarda literária, artística e política, bem como dois "eleições de rainhas" que funcionaram como pivôs da luta democrática.

Palavras-chave: vanguarda; Venezuela; rainhas de beleza; artes plásticas; abstração; eleições

RECIBIDO: 12 DE FEBRERO DE 2017. ACEPTADO: 27 DE ABRIL DE 2017. DISPONIBLE EN LÍNEA: 8 DE AGOSTO DE 2018

\section{Cómo citar este artículo:}

Lecuna, Vicente. "Reinas venezolanas del siglo XX. Populismo, abstracción y Estado". Cuadernos de Literatura 22.43 (2018): 75-96. https://doi.org/10.11144/Javeriana.cl22-43.rvsp 


\section{La otra cara}

En enero de 1928 aparece válvula en Caracas, considerada como la publicación que da inicio a la vanguardia literaria local. Varios de los escritores que publican en el único número de la revista formarían parte del canon de la literatura venezolana del siglo XX, como Miguel Otero Silva, José Antonio Ramos Sucre y Arturo Uslar Pietri. En febrero de ese mismo año, como parte de la celebración de la semana del estudiante y unos días antes de las fiestas de carnaval, un grupo de la recién fundada Federación de Estudiantes de Venezuela (presidida por Raúl Leoni, que sería presidente de 1965 a 1969) organizó una serie de eventos en Caracas, entre ellos la coronación de "Beatriz I" (Beatriz Peña), reina de los estudiantes. La coronación fue amenizada por un recital, en el que el escritor marxista Pío Tamayo participó con un poema suyo en homenaje a la reina, que terminaba haciendo una denuncia de la dictadura y un llamado a la lucha por la libertad: "¡y el nombre de esa novia se me parece a vos! Se llama: ¡LIBERTAD!’. Además de esto, durante toda la semana se dieron discursos y se hicieron desfiles que convirtieron un acto cultural en un acto político de protesta.

El régimen dictatorial de Juan Vicente Gómez respondió a estos hechos apresando a los estudiantes por 12 días. A este grupo de jóvenes se sumaron otros doscientos, en solidaridad con sus compañeros. Al cabo de esos días, el gobierno se vio obligado a ceder. Ante las protestas de los estudiantes de la Universidad de los Andes, en Mérida, y de muchas otras personas en varias ciudades del país, los liberó. De esta elección-celebración-protesta nacería la llamada Generación del 28, fundadora de la democracia en Venezuela. Sus miembros formarían parte de los partidos políticos Acción Democrática, Partido Comunista Venezolano y Unión Republicana Democrática. Un año después aparecería en España la novela Doña Bárbara (1929) de Rómulo Gallegos, que puede considerase como el epicentro de la literatura y la política del momento (y del siglo).

El grupo de escritores de válvula y el de los políticos de la Generación del 28, además del propio Gallegos, con el paso del tiempo establecerían el Estado venezolano de un modo particular, en una fórmula que guardaría una estrecha relación con las prácticas literarias y artísticas de la vanguardia. En esa negociación tomaría peculiar fuerza la literatura populista y el arte abstracto, este último sobre todo a partir de los años cincuenta y con un entusiasmo mayor a partir de los años sesenta.

La coronación de Beatriz I puede verse como un evento que saca la política nacional de las prácticas convencionales, que para la época estaban 
secuestradas por la dictadura o ni siquiera habían comenzado propiamente en Venezuela, y las abre a otras más heterodoxas y originales.

Otro evento de "belleza" que guarda una importante relación con la democracia venezolana y el establecimiento de un nuevo Estado es la elección de la Reina de la VII Serie Mundial de Béisbol Amateur, en 1944. Esta segunda elección se dirimió a través del voto universal, directo y secreto de los venezolanos mayores de 15 años. Las candidatas hicieron campaña en las ciudades de un país que no era, todavía, democrático, con el apoyo de periódicos, del Estado, de líneas aéreas y de partidos políticos. Estos últimos, que estaban formados, en su mayoría, por los miembros de la Generación del 28 (específicamente los del partido social demócrata Acción Democrática), vieron en este evento un pivote para promocionar el proyecto democrático, específicamente el voto universal, que aún no existía, y que era la demanda más importante del momento. Dos años después los venezolanos escogerían como presidente, en las primeras elecciones sin restricciones, a Rómulo Gallegos, maestro de la Generación del 28, cuya novela Doña Bárbara contenía, en clave literaria, el programa político de Acción Democrática que luego sería formulado en El Plan de Barranquilla (1931). Yolanda Leal, la reina del béisbol de 1944, y Rómulo Gallegos, el presidente de 1947, estaban unidos por otra variable: ambos eran maestros.

A partir de lo anterior me interesa discutir las prácticas específicas que le dan forma (verbal y visual) al Estado de la segunda mitad del siglo XX con el propósito de mostrar que, en el caso venezolano, este recibe una fuerte influencia de la vanguardia literaria y artística que lo determina, que le da un sentido particular que tendrá que ver con su entusiasmo, con sus alcances y límites. Quiero mostrar cómo el Estado venezolano logró "resolver" las contradicciones que supone el nacionalismo poscolonial a través de la peculiar reproducción de las palabras y las miradas, de una verbalidad populista y una visualidad abstracta que coopta el proyecto de vanguardia y a la vez es tomado por este proyecto, hasta llegar al Estado desarrollista. Quisiera discutir la otra cara del Estado mágico (Coronil): la cara vanguardista. También me interesa mirar qué fue lo que quedó de lado en esa relación, qué fue pasado por alto, negado y reprimido en esta negociación simbólica.

\section{Las palabras}

Uno de los poemas del libro El llano ciego (2006) de Igor Barreto comienza con la peculiar descripción del carácter de la escritura venezolana, específicamente la que se vincula a la nacionalidad: 
La escritura de las grandes planicies de mi país natal siempre fue la del verano: la naturaleza dominada por la luz, el viento, el fuego, las faenas heroicas del pastoreo, en fin, la pintura triunfante de un hombre a caballo librando una lucha titánica contra la inclemencia de lo lejano. (6o)

Barreto continúa con una caracterización del invierno planteando una oposición entre ambas escrituras: la del verano y la del invierno. Esa segunda estación, de la "vida interior", del hombre "recluido o asilado", queda de lado en Venezuela, según Barreto, desatendida por el énfasis nacionalista en el verano. El llano, de hecho, es el escenario de buena parte de la guerra de independencia: el llano de la sequía, por supuesto. La música llanera, por lo demás, es considerada como la música nacional por excelencia, así como la figura del llanero fue, durante todo el siglo XIX "un punto de referencia inevitable" (Rivas 31). No resulta, por tanto, nada caprichosa la caracterización de Barreto. Todo lo contrario. Doña Bárbara encaja muy bien dentro de su definición poética que, de hecho, parece haber sido formulada, precisamente, a partir de la novela de Gallegos: ocurre en el llano, en espacios llenos de luz, abiertos, donde hombres y mujeres a caballo luchan (chocan entre sí por el control de los rebaños y la tierra).

Escrita en medio de la primera gran expansión de la explotación petrolera, de la mano de las compañías transnacionales, Doña Bárbara es mucho más que una fábula de ganaderos; es, también, un programa político que define la actuación de las empresas transnacionales en Venezuela como problema (el personaje Mr. Danger representa este aspecto particular), al igual que el feudalismo que supone el gobierno dictatorial de Juan Vicente Gómez (representado en el personaje de Doña Bárbara). $\mathrm{Su}$ importancia no se acaba con estos asuntos generales. La novela de Gallegos, además, pone en escena un pacto populista del Estado venezolano basado en el romance, que promueve una peculiar modernización (Beverley "Novela y política"; Sommer; Skurski) y un proyecto político fundado en el mestizaje (Lasarte "Mestizaje y populismo"). El hecho de que sus equivalentes latinoamericanas -Sab (1841), Amalia (1851), María (1867), entre otras- hayan sido publicadas muchos años antes indica, además, una peculiaridad del caso venezolano: por este "retardo" la nacionalidad y el Estado venezolano del siglo XX estarían determinados por un proyecto de vanguardia, mientras que otros países latinoamericanos habrían encontrado inspiración para sus diseños nacionales en corrientes políticas y literarias previas. 
De acuerdo con lo que plantea Doris Sommer en su seminal libro Foundational Fictions (1991), Doña Bárbara (1929), en comparación con La vorágine (1924), puede leerse como un romance que pretende suturar, desde el populismo, una serie de heridas nacionales: "To read Doña Bárbara as a national romance is to read a series of defensively populist sutures where all of La vorágine's loose ends are anxiously bound up and where any bleeding between categories, such as male and female, is felt like a hemorrhage" (288). En este complejo proceso de reparación las diferencias se alteran, las categorías se mudan, los personajes se transforman al entrar en contacto. Santos Luzardo, el abogado civilizador que pretende establecer un nuevo orden nacional basado en la ley, por ejemplo, debe feminizarse (volverse tan apasionado como una mujer) para mantener el orden: debe enamorarse de la mestiza Marisela, su objeto de control (Sommer 289). Los hijos de esta unión poblarían el llano bajo un nuevo esquema, un pacto entre la élite doméstica (Santos) y el pueblo (Marisela). En este pacto se formularía una vía propiamente latinoamericana de acceso a la modernidad, que "resolvería", por un lado, el conflicto de las élites locales con las metrópolis -estableciendo una especie de justificación del dominio nacionalista endógeno-, y de las élites con el pueblo, mostrando su "derecho negociado" sobre la nación.

Javier Lasarte explica el argumento de John Beverley ("Novela y política") sobre el sentido del populismo en América Latina, su relación con Doña Bárbara y la política venezolana:

el populismo fue la respuesta histórica y modernizadora de la emergente burguesía nacionalista para superar lo que entendía como atraso de nuestras sociedades. Con el fin de desarrollar el mercado interno, este sector abandona el librecambismo económico y diseña una alianza antioligárquica y antiimperialista con el campesinado y sectores de la pequeña burguesía, las capas medias y el proletariado urbano. Su política exhibe en su listado de banderas: nacionalización de los recursos naturales, reforma agraria, educación popular, salud pública, democracia política, "la celebración de la cultura mestiza y el folklore nacional". ("Mestizaje y populismo" 167)

Esa alianza representada en la novela de Gallegos a través de una historia de amor (Sommer), es la que hace suponer a Beverley, según Lasarte, y otros, que el programa del populismo venezolano, particularmente establecido por el partido Acción Democrática, emana de Doña Bárbara. 
Doña Bárbara también es un hito de una de las dos "líneas fundamentales del proceso literario contemporáneo". Según Lasarte la primera vendría de José Martí, mientras que la otra vendría de Rubén Darío:

una surge de la reformulación crítica del criollismo y de la asunción de la literatura como un acto de reflexión implícita sobre la realidad nacional, mientras la otra supone la consideración del ámbito literario como realidad otra y superior. (Fuego y Nación 21)

La de la novela de Gallegos estaría atada a la martiana, así como el trabajo de los narradores José Rafael Pocaterra y Enrique Bernardo Núñez. De la segunda línea vendría el trabajo de Teresa de la Parra y Julio Garmendia. Lasarte identifica el proyecto populista de Gallegos con la idea de Martí de un mestizaje cultural "como alternativa para una sociedad futura, tan del gusto de una época llena de amerindias y razas có(s)micas, de proyectos culturales globalizadores" (Fuego y Nación 22). Esta original manera de ver las cosas, que se diferencia de la tradicional lectura sarmientiana de Doña Bárbara, marca una de las características principales del populismo venezolano, y establece uno de sus orígenes y genealogías más importantes.

Pero para que el mestizaje de Gallegos realmente pudiera funcionar, según Julie Skurski, la élite debía ser transformada en su contacto con el pueblo: "the nation could achieve the synthesis of forces promised by Latin America's mestizaje (racial mixing) only if its elite became morally and culturally transformed through its efforts to redeem and reshape the pueblo" (607). Skurski propone la síntesis entre la razón de la élite y la energía popular a través del amansamiento del terreno físico y social de la nación que supera, de manera original, el mero racionalismo determinista: "This discourse of authenticity posited a distinct Latin American path to civilization marked by the ascendancy of spiritual and telluric forces, guided by reason" (613).

La novela de Gallegos, además de lo anterior, cumplió con el propósito de difundir el proyecto político populista. Fue, de alguna manera, una novela de propaganda. Cuando la Generación del 28 logra hacerse del poder político en Venezuela en 1945 y llama a elecciones en 1947, Gallegos es propuesto como candidato presidencial por sus exalumnos, militantes en Acción Democrática. Para ese entonces Doña Bárbara ya era parte del imaginario nacional (y también latinoamericano). Acción Democrática había sido fundada en 1941: "with Gallegos as its president, and Doña Bárbara's elevation to the status of national novel accompanied the rise of the party" (Skurski 621). En 1943 la novela había sido llevada al cine con un guion del propio Gallegos, con Ma- 
ría Félix como protagonista. Desde entonces, la actriz mexicana fue conocida como La Doña por su extraordinaria interpretación. Para 1948, "Through Doña Bárbara, President Gallegos has also been a great popularizer of populist programs in Venezuela" (Sommer 274). En aquel entonces, la Generación del 28, guiada por Rómulo Betancourt, volvió del exilio "with models for establishing broad-based, populist politics" (Sommer 274). En ese retorno, y en los años siguientes, Doña Bárbara funcionaría como vehículo de promoción de las ideas populistas de Acción Democrática, alcanzando un público muy grande. La votación masiva a favor de Gallegos en 1947 demuestra el éxito de esta novela como proyecto pedagógico y a la vez de propaganda de la democracia.

Doña Bárbara también puede leerse como una forma actualizada de autodefinición y autolegitimación de una élite criolla que logra hacer una equivalencia entre la capacidad de escribir y la capacidad de ejercer el poder del Estado. En este sentido también encaja dentro de una tradición de mayor alcance que la venezolana:

Latin American literature not only served those nation-states by producing allegorical "foundational fictions", however; literature was also an ideological practice that interpelated the colonial and creole elites that engendered and ran these states, a form of self-definition and self-legitimation that equated the capacity to write and understand literature with the right to exercise state power. (Beverley, Subalternity and Representation 10)

Se combinará, entonces, con la literatura en directa relación al poder, como una práctica que escribe, suscribe y determina procesos de dominación. Desde este ángulo, Doña Bárbara puede verse como una intervención vanguardista dentro del Estado venezolano, una transformación que se injerta en el Estado como parte de un proceso de apropiación y de poder. No necesaria o únicamente como un proyecto adoptado o cooptado por el Estado, sino al revés: como un proyecto literario que supone la modernización populista, el antimperialismo, el nacionalismo y el mestizaje, como un pacto en el que se sutura y se repara, una "representation of unity that elided and concealed class differences" (Skurski 621). Esta representación propone un proyecto tutelado que permite la entrada del pueblo dentro del imaginario estatal en una posición activa y determinante, y, a la vez, un Estado que imagina una sociedad sin clases. Acción Democrática, no en balde, es un partido político que aspira a representar los intereses de varias clases sociales a la vez.

La importancia de Doña Bárbara también puede calcularse por el enorme esfuerzo de la dictadura de Marcos Pérez Jiménez, que derroca pre- 
cisamente a Gallegos, a la hora de construir un imaginario diferente, fundado en la derechista doctrina del Nuevo Ideal Nacional, que pretendía desplazar el poderoso proyecto de la novela populista de Acción Democrática. La dictadura encargó a Camilo José Cela la escritura de La Catira (1955): "la novela más aparatosamente venezolanista de cuantas hayan existido jamás" (Guerrero 135), que se ubica en los antípodas de Doña Bárbara; una novela que trata, de hecho "sobre la necesidad del caudillo" (Guerrero 136). El resultado no fue el esperado por la dictadura. La novela de Cela, que en muchos sentidos reproduce la de Gallegos pero desde un proyecto político opuesto, nunca logró desplazar a Doña Bárbara ni al proyecto socialdemócrata.

Al lado del proceso de canonización nacional de la novela Doña Bárbara, y casi en paralelo, los escritores que fundaron la revista de vanguardia válvula también acompañarían y determinarían la creación de ese mismo Estado populista imaginado por Gallegos. Para el momento de la aparición de su único número (1928) ya han entrado en escena: "una constelación de escritores renovadores respecto de los códigos modernistas, muchos de ellos de dimensiones continentales" (Lasarte, fuego y Nación 104). La revista válvula, entonces, cataliza una tendencia renovadora que ya existía, y que Gallegos también compartía. Además de la notable relación con la novela de Gallegos, los escritores de válvula tienen otro importante paralelo: "Nelson Osorio sostiene que el advenimiento de válvula es el equivalente cultural a la semana del estudiante en lo político" (Vilain y Rojas 20). Y así como la Generación del 28 determinó el carácter político populista de buena parte del siglo XX venezolano y particularmente del Estado, los escritores de la revista válvula determinarían la práctica literaria venezolana, optando muchos de ellos, más adelante, por un proyecto similar y a ratos prácticamente equivalente al de los políticos.

Cuando leemos los textos de válvula notamos que en sus páginas conviven escritores de la Generación del 18, posmodernistas, y poetas más jóvenes, más cercanos a la vanguardia y a la Generación del 28, todos hombres. Esta curiosa "heterogeneidad" se complica aún más cuando uno examina de cerca los textos:

Paradójicamente, autores de la Generación del 18 están representados por textos románticos o modernistas que no revelan ningún signo vanguardista [...] También aparecen textos regionalistas, como "El Llanero" de Julio Morales Lara, vuelto hacia la tierra y los típicos temas criollistas. (Schwartz 229)

Javier Lasarte coincide con esta caracterización, y va más lejos: "la plenitud de sus alcances, más allá de las declaraciones del manifiesto, es puesta 
en duda, dado la índole heteróclita y, lo que es peor, poco vanguardista de muchos de los textos que ahí se publican" (Fuego y Nación 103). Otra forma de entender este asunto tiene que ver con una negociación simbólica entre generaciones (modernistas, posmodernistas y vanguardistas), políticas (conservadores y no tanto) y estéticas (tradicionales y novedosas). Esta heterogeneidad se decantaría, con el tiempo, a favor de una literatura como la de Miguel Otero Silva, Arturo Uslar Pietri y Guillermo Meneses, de carácter nacionalista, que atendió los asuntos políticos e históricos del país, al igual que en prácticamente todo el resto de las vanguardias latinoamericanas. Otras formas de literatura compartirían el espacio cultural venezolano, pero esta, que coincide con la tendencia que Lasarte describe como derivada de Martí, es la que a la larga tomaría al Estado y se convertiría en su lengua, en un sentido populista y realista.

En el manifiesto "Somos" que aparece en la revista (atribuido a Uslar Pietri) se plantea como meta de la revista "renovar y crear". Los que suscriben, "un puñado de hombres con fe, con esperanza y sin caridad", ofrecen su "carne viva, porque bien es sabido que se pare con dolor". También dicen: "Abominamos todos los medios tonos". Y rechazan la tradición, como suelen hacerlo otros manifiestos de vanguardia. Pero el tono que predomina en el manifiesto no es precisamente radical, y el hecho de que esté acompañado por textos tan diversos suaviza su pretensión. Se insiste, por ejemplo, en el peculiar objetivo de sugerir: "El único concepto capaz de abarcar todas las finalidades de los módulos novísimos, literarios, pictóricos o musicales, el único, repetimos, es el de la sugerencia". En un gesto minimalista, en el párrafo siguiente, dicen que quieren "decirlo todo con el menor número de elementos posibles" (Vilain y Ajmad). Esta idea tiene que ver, según el manifiesto, con el poder de la metáfora.

Ese propósito inicial de la sugerencia del manifiesto "Somos" (que "Cuatro brochazos sobre un lienzo atrapen más trascendencia que todos los manuales de dibujo" y que, en música, "una sola nota encierre íntegro un estado del alma") se ubica en un lugar más cercano al de la mirada abstracta, que luego se insertaría en el Estado venezolano, como veremos más adelante, a través del arte oficial, y, a su vez, más lejano al de la lengua más bien realista del populismo y el nacionalismo, que tendría una relación más cercana con Doña Bárbara y que algunos escritores de válvula subscribirían.

Unos días después de la publicación de válvula, la Federación de Estudiantes organiza una serie de eventos que desembocan en una protesta contra la dictadura de Juan Vicente Gómez, como vimos al principio. En un 
momento estelar de la celebración, Pio Tamayo recita el poema "Homenaje y demanda del indio" que combina una serie de asuntos y estilos contradictorios (indigenistas, nativistas, paródicos, irónicos y políticos) dentro de un espíritu primordialmente vanguardista. La voz poética se define a sí misma como la de un "indio Tocuyo", y le habla a "su majestad Beatriz I". La reina de los estudiantes había sido electa de acuerdo a la tradición de carnaval, apenas unos días antes de que comenzara la celebración típica de esa fiesta. Raquel Rivas muestra, a través de citas de El Nuevo Diario, periódico oficial del gomecismo, que el régimen no quiso ver, durante toda la semana, ninguna rebelión. Más bien reseñó con entusiasmo cada paso que daban los estudiantes (Rivas 53-57).

Al final, el poema de Tamayo, que le ganaría la cárcel y a la larga la muerte, dice:

\section{Pero no, Majestad}

que he llegado hasta hoy,

y el nombre de esa novia se me parece a vos!

Se llama: ¡LIBERTAD!

Decidle a vuestros súbditos

tan jóvenes que aún no pueden conocerla-

que salgan a buscarla, que la miren en vos,

¡vos, sonriente promesa de escondidos anhelos!

Vuestra justicia ordene.

Y yo, enhiesto otra vez,

-alegre el junco en silbo de indígena romero-

armado de esperanzas como la antigua raza,

proseguiré en marcha.

Pues con vos, Reina nuestra,

juvenil, en su trono, ¡se instala el porvenir!

Según Raquel Rivas: "Una inversión simbólica se ha realizado aquí. $\mathrm{Y}$ en adelante, esa imagen del indio -mestizo- como hombre del pueblo orgulloso y altivo aparecerá de manera recurrente en las representaciones simbólicas del sujeto de la patria como fisura permanente en el imaginario colectivo" (Rivas 65-66). Esta representación acompañará, por ejemplo, la propuesta sobre el mestizaje que Lasarte observa en Doña Bárbara, como origen del sujeto popular de la democracia venezolana. Como respuesta a este poema y a otros que formaron parte del mismo recital del lunes 6 de febrero de 1928, y a los discursos de los jóvenes políticos Jóvito Villalba y 
Rómulo Betancourt (que abrieron y cerraron la celebración de la semana del estudiante, respectivamente), y a otros eventos, Juan Vicente Gómez, al finalizar la semana, apresó a los líderes durante algunos días. Unos meses después muchos de ellos serían encarcelados por un periodo mucho más largo, o serían expulsados del país. Otros, como el mismo Pío Tamayo, murieron en la cárcel. A partir de entonces, la Generación del 28 que nace de la semana del estudiante, se configura como el grupo político que conducirá al país hacia la democracia.

Es peculiar que el origen de esta Generación se encuentre en un evento cultural (Rivas 52), o más bien que los estudiantes hayan imaginado, en 1928, que un evento cultural, que sería (como de hecho fue) tolerado por el régimen dictatorial, pudiera producir un acto político: "A seemingly apolitical event, the coronation, provided an opportunity to the student movement to make its presence known in the heavily censored national newspapers" (Ochoa 26).

El poema de Tamayo y el recital a la reina Beatriz I revelan una manera propiamente vanguardista de hacer política, una forma que desestabiliza al régimen dictatorial y anuncia la llegada de la libertad y la democracia. Ante la ausencia de mecanismos protocolares para el ejercicio político (partidos políticos libres, fundamentalmente), los eventos no-protocolares de la semana del estudiante, a la larga, convocarían el apoyo del pueblo venezolano, que entendió como injusta la reacción del régimen de Gómez contra los estudiantes. Ese apoyo, en parte, tuvo que ver con la semejanza de la celebración de la semana del estudiante con las celebraciones tradicionales de carnaval: "los festejos fueron sin duda pensados para formar parte de la cultura callejera que se asociaba con los actos del carnaval" (Rivas 55). El establecimiento de ese paralelo es una de las estrategias vanguardistas de los estudiantes. Ese mismo apoyo es el que más adelante convocaría la elección de Rómulo Gallegos como presidente, en gran medida por su popular novela. En este sentido el poema de Tamayo, así como los otros eventos que acompañaron el recital, aglutinaron un espíritu de lucha que estaba dormido, o que no había encontrado ningún canal de expresión. Con el poema de Tamayo hace entrada en la política venezolana una forma de ejercicio de los derechos civiles que ya no es militar, que ya no es del siglo XIX, que es propiamente de vanguardia: muestra "la irrupción de nuevos modos de escenificar la política y de politizar la cultura" (Rivas 52). Esos nuevos modos serían, a la larga, característicos del Estado venezolano.

En el segundo día de la semana del estudiante, el martes 7, se realizó un desfile de automóviles por Caracas, que repetía la tradicional ruta del 
carnaval. A la cabeza se escuchaba un himno que decía: „iAla y balaja!! iiSaca la pata lajá!! ii Y ajá!! iiy saca la pata lajá!! "El extraño canto universitario sonó en las calles como una consigna, aunque no decía nada en sí mismo" (Rivas 57). Este dato, que no decía nada en sí mismo, muestra, al lado del poema de un "indio" a una reina, el extraordinario efecto político de la forma sin contenido: la consigna en sí, la forma, constituyó un hecho político que el régimen no entendió en su momento, pero que fue entendido claramente por los militantes y por el pueblo como un llamado en contra de la dictadura y por la libertad.

Como cierre de la semana, Rómulo Betancourt hace un discurso en el que incorporó a los sujetos populares marginados y particularmente a las mujeres: en esta intervención "se legitima la emergencia de un espacio discursivo que da cabida a un tipo de letrado comprometido con las luchas del pueblo [...] que pretende fundirse con la voz del otro para producir su discurso en términos populistas" (Rivas 66). Al día siguiente El Nuevo Diario abandona las reseñas generosas y anuncia que las autoridades de la Universidad Central de Venezuela han sido destituidas. Al culminar la semana los líderes estudiantiles son detenidos, como vimos.

Es así como el populismo de Doña Bárbara tiene un aliado en el populismo de la Generación del 28, que es anterior a la publicación de la novela, y que sin duda conecta a los alumnos con su maestro, así como a los líderes, escritores e intelectuales con el pueblo venezolano. Se construye de esta manera la base del pacto populista, en clave literaria (Doña Bárbara) y en clave cultural (semana del estudiante y elección de Beatriz I).

Con la muerte del Juan Vicente Gómez (1935) se abrió una pequeña ventana de tolerancia y se inició un incipiente proceso de reforma de Estado. El llamado programa de febrero de Eleazar López Contreras (1936) recoge parte de este espíritu. Según la muy influyente y polémica frase de Mariano Picón Salas, Venezuela, con la muerte de Gómez, habría llegado tarde al siglo XX: "Podemos decir que con el final de la dictadura gomecista comienza apenas el siglo XX en Venezuela. Comienza con treinta y cinco años de retardo" (17). Esta tesis no tiene todos los asideros (una primera modernidad venezolana es notable a finales del siglo XIX) y ha sido desmentida en libros como Las luces del gomecismo (1987) de Yolanda Segnini, por ejemplo, pero sigue sosteniéndose hoy en día como una especie de mito nacional, como un mito de la misma Generación del 28. "Homenaje y demanda del indio" de 1928 y Doña Bárbara de 1929 de alguna manera, en realidad, podrían mover la fecha del mito apenas unos años hacia atrás. A esta combinación de textos fundacio- 
nales del populismo venezolano habría que agregar la poesía de Andrés Eloy Blanco, que cumple un periplo que va de la vanguardia, Baedeker 2000 (1935), al populismo del poema antirracista Píntame angelitos negros (circa 1944), por ejemplo, reproducido en muchas interpretaciones musicales a lo largo del siglo XX; la primera de ellas en el bolero del mexicano Manuel Álvarez Maciste. Además, han interpretado Píntame angelitos negros Cat Power, Celia Cruz, Roberta Flack, Lola Flores, Eartha Kitt, Los Ángeles Negros, Javier Solís y Chavela Vargas, entre otros.

\section{Las miradas}

Así como Doña Bárbara puede ser considerada como la ficción fundacional de Venezuela, la obra del artista moderno Armando Reverón, a su vez, se constituye como su imagen ficcional. Sin embargo, el estatuto de Reverón como artista nacional por excelencia no penetra el discurso estatal, por lo menos no lo hace de la misma manera que Doña Bárbara. El Estado venezolano recurrirá a artistas nativistas y abstractos para mirarse y mirar al país en los años 50, durante la dictadura de Marcos Pérez Jiménez, y luego especializará su mirada en torno a la abstracción constructivista y el cinetismo, ya en plena democracia desarrollista (Pérez Oramas).

El Estado venezolano también recurrirá a la arquitectura modernista (por ejemplo, la Ciudad Universitaria de Carlos Raúl Villanueva, inaugurada en 1954) y a la llamada arquitectura neoclásica (por ejemplo, el Paseo los Próceres de Luis Malaussena, inaugurado en 1956), para configurarse en clave moderna sobre una larga serie de edificaciones como represas, hospitales, escuelas, universidades, museos, aeropuertos y sistemas de transporte. Este proceso también se alimentaría del aporte del diseño gráfico, sobre todo del trabajo de Gerd Leufert que identificaría a muchas instituciones del Estado.

En 1944, cuando Armando Reverón ya tenía más de veinte años pintando en Macuto y ya había hecho sus misteriosas Muñecas, se produce en Venezuela la elección de una nueva reina en un certamen que confirmaría el sentido popular de la democracia y del Estado venezolano. Al igual que en 1928, se trata de un evento que no se corresponde directamente con las prácticas políticas convencionales y que no sucede dentro de los escenarios protocolares de la política nacional. Precisamente por esta dislocación logra convertirse en una referencia en un país que todavía en 1944 no conocía el voto universal, directo y secreto para la elección del presidente. Antes de entrar en el asunto de las políticas visuales del Estado venezolano quisiera discutir este nuevo 
evento de belleza, para enlazarlo con el mencionado anteriormente y con lo que luego será la forma de la mirada del Estado venezolano.

A Venezuela, que había logrado convocar un enorme entusiasmo popular por haber ganado la IV Serie Mundial de Béisbol Amateur celebrada en La Habana en 1941, le fue concedida la sede para la edición de 1944 . Como parte del evento se debía escoger una reina. Después de cierto debate en torno al método electoral, la comisión organizadora venezolana decidió adoptar el voto universal, directo y secreto de todos los venezolanos mayores de 15 años. La primera vez que los venezolanos pondrían en práctica este sistema lo harían para elegir una reina (y no un presidente), y de belleza (no nacional). Para ese momento, el béisbol ya era el deporte nacional por excelencia, desde que las compañías petroleras norteamericanas le dieran un enorme apoyo durante la primera mitad del siglo XX. Esta característica diferencia a Venezuela del resto de los países de América del sur (aficionados al futbol) y la acerca al Caribe.

Los partidos habían sido legalizados apenas unos años antes por el gobierno de transición del general Isaías Medina Angarita, que era uno de los militares vinculados a la dictadura de Juan Vicente Gómez. Para aquel entonces, votaban los hombres venezolanos, mayores de 21 años, que supieran leer y escribir, y lo hacían solamente para elegir representantes ante los organismos locales. De esta manera quedaban excluidas las enormes mayorías del país.

Las candidatas más importantes y activas a reina de la VII Serie Mundial del Béisbol Amateur fueron Oly Clemente, de clase alta, cuyo padre era el secretario del Presidente General Isaías Medina Angarita, y Yolanda Leal, de Monte Piedad, un barrio popular de Caracas. Ambas candidatas, que eran deportistas y a la vez apasionadas fanáticas, y que compitieron con una extraordinaria camaradería, hicieron campaña por todo el país con el apoyo del Estado, particulares, compañías privadas, periódicos y líneas aéreas. La gente las recibía en masa, causando verdaderos tumultos. En algún momento corrió de boca en boca un lema: "Oly Clemente para la gente decente y Yolanda Leal para la gente vulgar". Esto causó la indignación de muchos venezolanos, que por eso se inclinaron con mayor entusiasmo hacia la candidatura de Yolanda Leal, que ya contaba con el apoyo mayoritario, de acuerdo a los testimonios que aparecen en el documental La reina del pueblo de Juan Andrés Bello (2010), que incluye una entrevista con la propia Yolanda Leal.

Mientras las candidatas recorrían el país buscando apoyo, se convoca la elección para escoger los Consejos Municipales de algunos Estados. Los parti- 
dos participan bajo protesta; exigen el voto universal, directo y secreto para estas elecciones, que al cabo no logran. Lo que el Consejo Supremo Electoral niega es, entonces, logrado en el método de elección de la reina. Los partidos políticos encuentran en la elección de la reina la oportunidad de poner en práctica una especie de ensayo democrático, al margen del Estado. El sufragio se realiza en cines y estadios deportivos, en espacios civiles que no tiene connotaciones políticas. Acción Democrática apoya la candidatura de Yolanda Leal y la elección se torna, de esta manera, en una especie de plebiscito simbólico sobre la presidencia del General Isaías Medina Angarita. Yolanda Leal, a su vez, se declaraba admiradora de Rómulo Gallegos, Andrés Eloy Blanco y Rómulo Betancourt, líderes de Acción Democrática. Yolanda Leal, incluso, participa en un mitin de este partido, aunque declara que nunca tuvo militancia política (Bello).

La elección también adquiere las características de una confrontación entre grupos étnicos, de clase y de poder: Oly Clemente era blanca, de clase alta y era vista como partidaria del régimen, mientras que Yolanda Leal no era blanca, era de clase popular y no era vista como partidaria del régimen. Cuando al final del certamen se declara ganadora, por barrida, a Yolanda Leal, los líderes de Acción Democrática hacen una lectura política de esa victoria: según ellos se demostraba que Venezuela, gracias a la elección de Beatriz I, estaba lista para el voto universal, directo y secreto. Un año después, en compañía de un grupo de militares, Acción Democrática protagoniza un exitoso golpe de Estado contra Isaías Medina Angarita y llama a elecciones en 1947. Con el apoyo mayoritario de los venezolanos, Rómulo Gallegos, maestro como Yolanda Leal, se convierte en el primer Presidente electo por el pueblo. La lucha por la democracia, que había comenzado en 1928 con la elección de Beatriz, por fin alcanzaba un primer éxito, en gran medida gracias a la elección de Yolanda Leal, otra reina, en 1944. Pero no habría de durar mucho. Antes de cumplir un año como presidente, Gallegos es derrocado por el mismo grupo de militares que había acompañado a Acción Democrática en el golpe de 1945. Desde entonces se instaura una dictadura en Venezuela que unos años después impondría a Marcos Pérez Jiménez como presidente hasta 1958, cuando la misma Generación del 28 retoma el poder y llama a elecciones libres, de nuevo.

Tanto en el caso de Beatriz I como de Yolanda Leal, se pone en escena la importancia política de las reinas de belleza en Venezuela, que, al lado del petróleo, serían la referencia nacional durante muchos años: "until the Bolivarian Revolution, beginning with the election of Hugo Rafael Chávez Frías in 1998, Venezuela was not well known to outsider for much else besides beauty 
queens and petroleum" (Ochoa 7). Estas dos características se combinaron en los tanqueros que transportaban el petróleo a su mercado hasta el fallido golpe de Estado que sacó de poder a Hugo Chávez por apenas unas horas en 2002. Estos buques llevaban los nombres de las reinas, de las Miss Universo y Miss Mundo venezolanas: Maritza Sayalero, Pilín León, etc. Después de 2002 estos nombres fueron cambiados. El concurso de Miss Venezuela había nacido en 1952 durante la dictadura de Marcos Pérez Jiménez. En 1955, Susana Dujim se había convertido en la primera Miss Mundo venezolana, iniciando una larga "dinastía de soberanas".

Aunque formen un riguroso paralelo, las artes visuales venezolanas del siglo XX tienen una historia muy distinta a la de la literatura. Unos años antes de que se publicara la revista válvula, Armando Reverón se había retirado del Círculo de Bellas Artes y se había radicado en el litoral central venezolano. A partir de entonces realizará una serie de pinturas y objetos que marcan el origen de la modernidad artística venezolana. En el manifiesto "Somos" de válvula uno puede notar el claro ejercicio consciente de una voluntad moderna que desea poner en práctica un programa: "venimos a reivindicar el verdadero concepto del arte nuevo". En los paisajes, desnudos, retratos, muñecas y objetos -así como en los rituales a la hora de trabajar- de Armando Reverón uno no encuentra nada similar. Luis Enrique Pérez Oramas, de hecho, dice que "las más sorprendentes realizaciones de Reverón no fueron el resultado de una voluntad moderna". Sin embargo, sí se encuentra en el trabajo de Reverón "la evidencia de que en su pintura el paisaje funciona como un espejo para la pintura misma, como el pretexto de un proceso de autorreflexión en el que la pintura alcanza a producir formas y figuras seminales" (20). Esto "hace de Reverón la encarnación primera de una modernidad involuntaria, acaso 'deformada', ciertamente "residual'" (22). ¿'Modernidad involuntaria? ¿Acaso es posible? En el caso de la historia literaria uno observa todo lo contrario: una voluntad que se pone en práctica en el manifiesto "Somos", en el poema de Pío Tamayo a la reina de los estudiantes, en la opción por una literatura populista de Rómulo Gallegos y en la poesía de Andrés Eloy Blanco. El Estado venezolano tomaría la literatura populista como política verbal porque ponía en clave simbólica los mismos preceptos sociales del propio Estado: mestizaje, antiimperialismo, educación masificada, etc. En el caso de las artes visuales esta conexión social no fue simultánea: "No hubo en Venezuela, como sí en México o Brasil, ninguna temprana articulación consciente entre lo social (o lo político) y lo moderno" (Pérez Oramas 23). Tanto el trabajo de Reverón como el de Francisco Narváez así lo atestiguan. 
Después de que un grupo de militares sacara del poder a Rómulo Gallegos, el Estado venezolano adoptará el nativismo alegórico, por un lado, y la modernidad constructiva, por otro, como políticas del Estado, dos lenguas distintas en una misma boca, podríamos decir. Por un lado, el trabajo del pintor Pedro Centeno Vallenilla y del escultor Francisco Narváez, y por el otro el trabajo arquitectónico de Carlos Raúl Villanueva (Ciudad Universitaria de Caracas, por ejemplo): "el nativismo alegórico que sería promovido como ideología oficial de la dictadura bajo la denominación de una 'nuevo ideal nacional' y la modernidad constructiva financiada por la misma dictadura y utilizada por ésta como vitrina de su propia grandeza política" (Pérez Oramas 28). A esta ecuación se sumaría el arte abstracto (que precisamente domina en la Ciudad Universitaria de Caracas -Jean Arp, Miguel Arroyo, Armando Barrios, André Bloc, Alexander Calder, Omar Carreño, Carlos González Bogen, Henri Laurens, Fernand Léger, Mateo Manaure, Pascual Navarro, Alirio Oramas, Alejandro Otero, Antoine Pevsner, Braulio Salazar, Víctor Vasarely y Oswaldo Vigas).

A partir de El salón 1958 se consagra plenamente la tesis de la abstracción (Alejando Otero), y luego del cinetismo (Jesús Soto y Carlos Cruz Diez) como política visual del Estado: "lo que terminó por darle un carácter distintivo al Salón fue el juicio oficial favorable a la abstracción constructiva, al serles otorgados a representantes suyos los Premios Nacionales" (Navarrete 13). El nativismo es entonces dejado de lado con la democracia, curiosamente, por lo menos como mirada del Estado, en tanto que la tendencia moderna internacional, el arte abstracto y el cinetismo son asumidos por el Estado y se vuelven, irónicamente, discursos nacionales (Pérez Oramas 34). Ese mismo año de 1958 el dictador Marcos Pérez Jiménez había huido del país y otra junta cívico militar, con una orientación democrática, tomó el poder. Con el tiempo, el peso de la abstracción constructivista desbordaría los límites del Estado y llegaría, incluso, a estar asociado a la nación, a su identidad, o mejor dicho a una nueva identidad recién estrenada: "la abstracción constructiva y su afín el cinetismo se transformaron en un componente de la 'identidad' al hacerse patrimonio de un amplio sector de peso en la sociedad, penetrar en la vida cotidiana y emblemática -incluso internacionalmente- el arte profesional del país durante décadas" (Navarrete 18). Así mismo pasaría a ser paradigmática:

la abstracción geométrica se iba consolidando como un modelo canónico del arte venezolano después del Proyecto de integración de las artes de la Universidad Central de Venezuela del Arquitecto Carlos Raúl Villanueva, para luego 
agregar el arte cinético a partir del éxito internacional alcanzado por Jesús Soto y Carlos Cruz Diez. (Rangel)

La adopción de la abstracción como sentido del Estado, como política visual en sí misma, supone una interesante contradicción: "solo el país podía alcanzar el progreso y la independencia cultural adaptando estas formas universales de la modernidad visual" (Rangel). Las formas universales garantizarían el desarrollo y la liberación nacional. Esta contradicción es la misma que, de otra manera, sucede con el populismo: las élites de los Estados poscoloniales latinoamericanos, en busca de un desarrollo propio, se ven obligadas a recurrir a modelos coloniales, los mismos que ponen en una situación de desventaja a sus Estados: "This split has characterized the elite's effort to assert authority in Latin America, as its national discourse embraced metropolitan models in the name of independence" (Skurski 112).

El papel de las élites ilustradas en esta traducción es fundamental: son las que construirían una independencia con el mismo lenguaje de la dependencia. La obra de Gallegos muestra esta contradicción. Y es aquí entonces donde por fin esa voluntad se compagina con la abstracción. Ambos hacen un doble juego entre las metrópolis y las periferias, proponiendo una independencia con el mismo lenguaje, las mismas formas y los mismos contenidos de la dependencia:

Las formas del abstraccionismo constructivista resultaron atractivas para el proyecto de modernización de las élites intelectuales, económicas y culturales en tanto que ostentaban la promesa de establecimiento del orden racional en un país minado por el militarismo y el subdesarrollo. (Rangel)

\section{El Estado de la vanguardia}

De esta contradicción -abstracción en el arte y populismo en la literaturaemerge un Estado democrático que se lee y se hace leer como nacionalista (venezolano, local y moderno, aunque no-tecnócrata) y que se mira y se hace mirar como formalista (eurocentrado, universal, moderno y tecnócrata). Estas dos tendencias estaban dentro de la vanguardia de los años 20 de manera consciente en el grupo literario de válvula y en la literatura populista de Rómulo Gallegos y Andrés Eloy Blanco, y de manera inconsciente en la obra de Armando Reverón. Luego, en la obra de artistas como Alejandro Otero, Carlos Cruz Diez y Jesús Soto, se asume esa conciencia moderna, de manera plena. Ambas muestran la creativa ambigüedad del proyecto democrático venezolano que apostaba por una "modernidad pro- 
pia", y que entonces debía calcularse en dos direcciones a la vez, apostar a dos números distintos, la postulación de una nación metropolitana por un lado y la vez periférica, por el otro:

In order for 'developing' countries to secure a sovereign and solvent condition in the world, populists tend to advocate further development; but since what is being protected is a certain national difference that resists becoming an extension or a clone of the industrial powers, populists also tend to celebrate local traditions. (Sommer 283)

Esta apuesta se materializa en una literatura y una palabra populista y en un arte y una mirada abstracta que dan lugar a una solución que incorpora las contradicciones en el rostro nacional.

Hacia finales de la década del sesenta ocurre un fenómeno que muestra una ruptura dentro de las políticas visuales y verbales del Estado. La exhibición Imagen de Caracas (1968) se inaugura en la capital, en los terrenos de lo que sería el moderno conjunto Parque Central unos años después. En este performance-instalación, dirigido por el artista Jacobo Borges y montado en un dispositivo creado por el arquitecto Juan Pedro Posani, participan cineastas, pintores, músicos, escritores, actores, en la construcción de una versión irreverente y furiosamente vanguardista de la historia de Caracas. Llena de saltos temporales y provocaciones, haciéndose eco de las denuncias de los grupos de izquierda sobre la naturaleza severamente colonialista de la identidad caraqueña, la obra fue cerrada a los pocos meses, pero marcó un hito en la historia del arte venezolano, sobre todo en lo que sería conocido como arte no-objetual (Rangel). La novedad en este caso es que el Estado, que patrocinó Imagen de Caracas a través del Consejo Municipal, abandonó la literatura populista y el arte abstracto y adoptó por unos meses al arte no objetual, el neofigurativismo y la vanguardia no-populista -esa que estuvo vinculada al grupo de vanguardia radical El techo de la ballena, que apoyó la lucha armada-. En esta especie de excepción que se configura en torno a la relación del Estado con Imagen de Caracas se muestran los límites de la política populistaabstracta. En el momento en que se buscó incorporar una versión radical, un sentido extremo de la lengua y la mirada, el pacto se rompió. El Estado que había adoptado la vanguardia artística y el populismo literario durante tantos años para darle forma a su agencia política no logró dar el salto hacia una representación radical, o más bien logró hacerlo apenas por un momento, y unos meses después se arrepintió. 
En 1981 la venezolana Irene Sáez es coronada como Miss Universo. Unos años después comienza una carrera política que la llevaría a convertirse en Alcaldesa de Chacao (en Caracas) y luego en candidata presidencial en 1998. En diciembre de ese año pierde las elecciones. Hugo Chávez, su adversario, era un militar retirado que había participado en un fallido golpe de Estado en 1992. Se iniciaría, desde entonces, la llamada Revolución Bolivariana. El verbo populista de Rómulo Gallegos y Andrés Eloy Blanco se mantendría en la lengua del Estado, mientras que la abstracción sería progresivamente dejada de lado y substituida por el figurativismo de un nuevo muralismo inspirado en artistas como Régulo Pérez, indicando un nuevo giro en los sentidos del Estado, hacia una mirada que ya no es la misma del estado desarrollista que se gestó en 1928 y dominó el espectro político hasta 1998.

El Estado venezolano ha sido calificado por Fernando Coronil como mágico. En el corazón de esta magia estatal están los ciudadanos y el petróleo: la deificación del Estado tuvo lugar como parte de la transformación de Venezuela en nación petrolera que, en tanto tal, se percibía como una nación con dos cuerpos: un cuerpo político compuesto por sus ciudadanos y un cuerpo natural cuya materia era su rico subsuelo. Al condensar en sí los múltiples poderes dispersos en los dos cuerpos, el Estado apareció como un agente único dotado del poder mágico de rehacer la nación. (Coronil 4 )

Yo agregaría que la magia se mantuvo, además, sobre los sentidos del Estado, sobre sus palabras y sus miradas, que combinaron y resolvieron, en dos registros distintos y contradictorios, las ansiedades del pacto populista venezolano. Se sostuvo sobre proyectos metropolitanos que justificaban su independencia y su carácter local. En el camino se produjeron visualizaciones y narraciones nacionales ambiguas (Skurski) que revelaron las ficciones que ya no son fundacionales, sino las que más bien sujetan a la nación desde la continuidad.

Aunque el siglo XX en Venezuela "comienza con treinta y cinco años de retardo" (Picón Salas), lo hace a toda velocidad de la mano de la vanguardia. Eso le daría palabra e imagen al Estado, le darían una consistencia peculiarmente moderna, que promovió cambios y desechó las atávicas tradiciones clasistas que venían del siglo XIX y del entresiglo. Al cabo de algunos años, el Estado venezolano, apoyado en la explotación del petróleo, en el populismo y en la abstracción, lograría "alcanzar" a sus pares latinoamericanos, aún organizados sobre ideas conservadoras formuladas en el siglo XIX. 


\section{Obras citadas}

Barreto, Igor. El llano ciego. Caracas: Sociedad de Amigos del Santo Sepulcro, 2006. Impreso. Bello, Juan. Andrés. La reina del pueblo. Caracas: Producciones Triana, 2010. Filme. Beverley, John. "Novela y política en América Latina. (De Doña Bárbara a Cien años de soledad". Del Lazarillo al sandinismo. Minneapolis: Institute for the Study of Ideologies and Literatures, 1987. 99-122. Impreso.

Beverley, John. Subalternity and Representation. Arguments in Cultural Theory. Durham - London: Duke University Press, 1999. Impreso.

Coronil, Fernando. El Estado Mágico. Naturaleza, dinero y modernidad en Venezuela. Caracas: CDCH - Nueva Sociedad, 2002. Impreso.

Guerrero, Gustavo. Historia de un encargo: "La catira" de Camilo fosé Cela. Barcelona: Anagrama, 2008. Impreso.

Lasarte, Javier. Fuego y Nación. Posmodernismo y vanguardia en Venezuela. Caracas: Fundarte, 1995. Impreso.

Lasarte, Javier. "Mestizaje y populismo en Doña Bárbara: de Sarmiento a Martî". Iberoamericana 24.2.3 (2000): 164-186. Impreso.

Navarrete, José Antonio. Arte en libertad. Salón 1958. Caracas: Museo Alejandro Otero, 1999. Impreso.

Ochoa, Marcia. Queen for a Day. Transformistas, Beauty Queens and the Performance of Feminity in Venezuela. Durham - London: Duke University Press, 2014. Impreso.

Pérez Oramas, Luis Enrique. Hacia el siglo XX venezolano, artes plásticas, academicismos, implantaciones y localidades. Caracas:

Colección Patricia Phelps de Cisneros, 200o. Impreso.

Picón Salas, Mariano. "La aventura venezolana". Viejos y nuevos mundos. Caracas: Biblioteca Ayacucho, 1983. Impreso.

Rangel, Gabriela. "El arte de los rincones: notas sobre las experiencias no-objetuales en Venezuela". Hemispheric Institute E-misférica. N.d. Web. 2 de febrero de 2016.

Rivas, Raquel. Bulla y buchiplumeo. Masificación cultural y recepción letrada en la Venezuela gomecista. Caracas: La Nave Va, 2002. Impreso.

Schwartz, Jorge. Las vanguardias latinoamericanas. Textos programáticos y críticos. DF: Fondo de Cultura Económica, 2002. Impreso.

Segnini, Yolanda. Las luces del gomecismo. Caracas: Alfadil Ediciones, 1987. Impreso. Skurski, Julie. "The Ambiguities of Authenticity in Latin America. Doña Bárbara and the Constructions of National Identity". Poetics Today 15.4 (1994): 605-642. Impreso.

Sommer, Doris. Foundational Fictions. The National Romances of Latin America. Berkeley: University of California Press, 1991. Impreso.

Vilain, Roger y Diego Rojas Ajmad. Revista válvula (1928). Edición facsimilar.

Mérida: Ediciones Actual - Universidad de los Andes, 2011. Impreso. 